\title{
Polypoid arteriovenous malformation of the ureter mimicking a fibroepithelial polyp, a case report
}

\author{
C.S. ten Donkelaar ${ }^{*}$, A.C. Houwert, F.J.W. ten Kate and M.T.W.T. Lock
}

\begin{abstract}
Background: Arteriovenous malformations (AVM) of the urinary tract are extremely rare. To the best of our knowledge, only three case of AVM of the ureter have been described in the literature so far.

Case presentation: We present an additional, fourth case of an AVM of the ureter, clinically presented as asymptomatic haematuria and an obstructive process in the left ureter. Ureteroscopic evaluation revealed a fibroepithelial polypoid-like lesion in the proximal ureter. After biopsy showed a benign lesion, the lesion was treated with the 2-um continuous wave (cw) thulium laser. Histopathological examination revealed a polypoid laesion caused by a circumscribed arteriovenous malformation. Almost four years after operation the patient remains asymptomatic and free of recurrence.
\end{abstract}

Conclusion: Arteriovenous malformations of the urinary tract are extremely rare. We presented a fourth case of a arteriovenous malformation of the ureter.

Keywords: Arteriovenous malformation, Polyp, Ureter, Case report

\section{Background}

Ureteral tumours are rare, and $20 \%$ of these tumours are benign [1]. Fibroepithelial polyps (FEP) are the most common benign ureteral tumours. Approximately 220 cases have been described [2,3]. In recent years, most cases of FEP have been presented in China and Japan, which suggests that this disease is more prevalent in East Asia [4]. Another benign ureteral tumour is the arteriovenous malformation (AVM). AVMs of the urinary tract are also rare: to our knowledge only three cases have been described in the literature, two of which consisted of a polypoid mass [5-7]. We present the fourth case of an AVM of the ureter in a patient with macroscopic haematuria, which mimics a fibroepithelial polyp.

\section{Case Presentation}

A 41 year old woman was referred to our hospital for asymptomatic macroscopic haematuria, which was discovered during a procedure of in vitro fertilisation. She

* Correspondence: C.S.tenDonkelaar-2@umcutrecht.nl

University Medical Center Utrecht, Heidelberglaan 100, 3584 CX Utrecht, The Netherlands experienced some discomfort in the middle lower quadrant of the abdomen. There was no history of urinary tract infections or stones. Physical examination findings were within normal limits. Urinalysis showed haematuria, and cytology revealed atypical transitional cells. Ultrasonography of the kidneys presented neither hydronephrosis nor urolithiasis. Abdominal-pelvic computed tomography revealed a thickened ureteral wall of the proximal part of the left ureter. Moreover, a presumed blood clot was observed in the ureter for which there was no suspicion of tumour. Retrograde pyelography revealed a filling defect of the left ureter from L4-L5 [Fig. 1].

Ureteroscopy showed a $3 \mathrm{~cm}$, firm polypoid-like lesion with a glistening appearance. A biopsy of this polypoid-like lesion demonstrated fibrosis, with no signs of malignancy. It was decided to perform ureteroscopic polypectomy to remove the lesion by the $2-\mu \mathrm{m} \mathrm{cw}$ Thulium laser; during the intervention, no bleeding occurred [see Additional files 1 and 2]. A 6-Fr double J-stent was left in place. Histopathological examination revealed a polypoid tissue specimen composed of mucosa without adjacent muscularis propria. The mucosa was covered by uneventful transitional cell epithelium and focally 


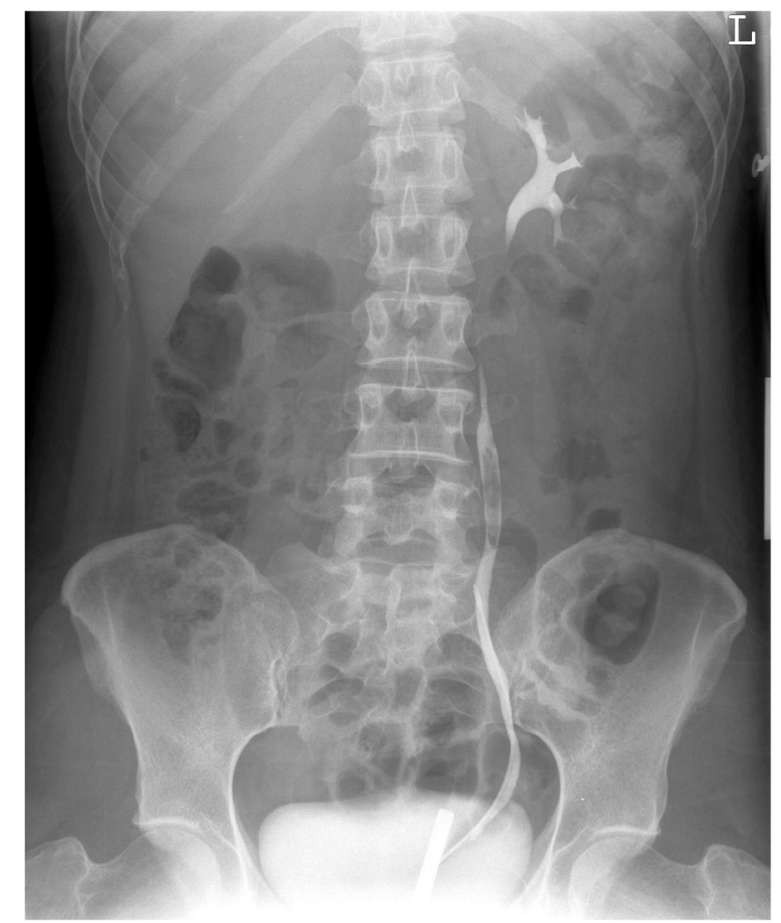

Fig. 1 Retrograde pyelography with a filling defect in left ureter from L4-L5

subepithelial hyalinised stroma. The tunica propria presented a circumscribed collection of smaller and larger arterial and venous type blood vessels. Some vessels showed asymmetrical thickening of the muscle wall. These findings were consistent with the diagnosis of AVM [Fig. 2a and b]. The patient had an uneventful recovery. The double J-stent was removed after two weeks, no recurrence was observed in the follow-up with abdominal-pelvic computed tomography and urine cytology during a period of eight years.

\section{Discussion}

AVMs of the ureter are very rare. To our knowledge only three cases have been described [5-7]. The first case was a 34 year old woman with intermittent gross haematuria together with mild left flank pain. Urine cytology was initially reported as demonstrating malignant cells; further examination revealed that these were benign cells of nontransitional origin. A retrograde pyelogram showed a filling defect in the mid-ureter. Ureteroscopy revealed a polyp. An excisional biopsy was performed and histological examination demonstrated the presence of an AVM [7]. In the second case, a 19 year old woman presented with repeated total haematuria with intermittent right loin discomfort associated with the attacks of haematuria. Right retrograde pyelography showed a filling defect of the distal end of the ureter. Ureteroscopy revealed an inflamed, ulcerated, 'cobblestone'-like mucosa

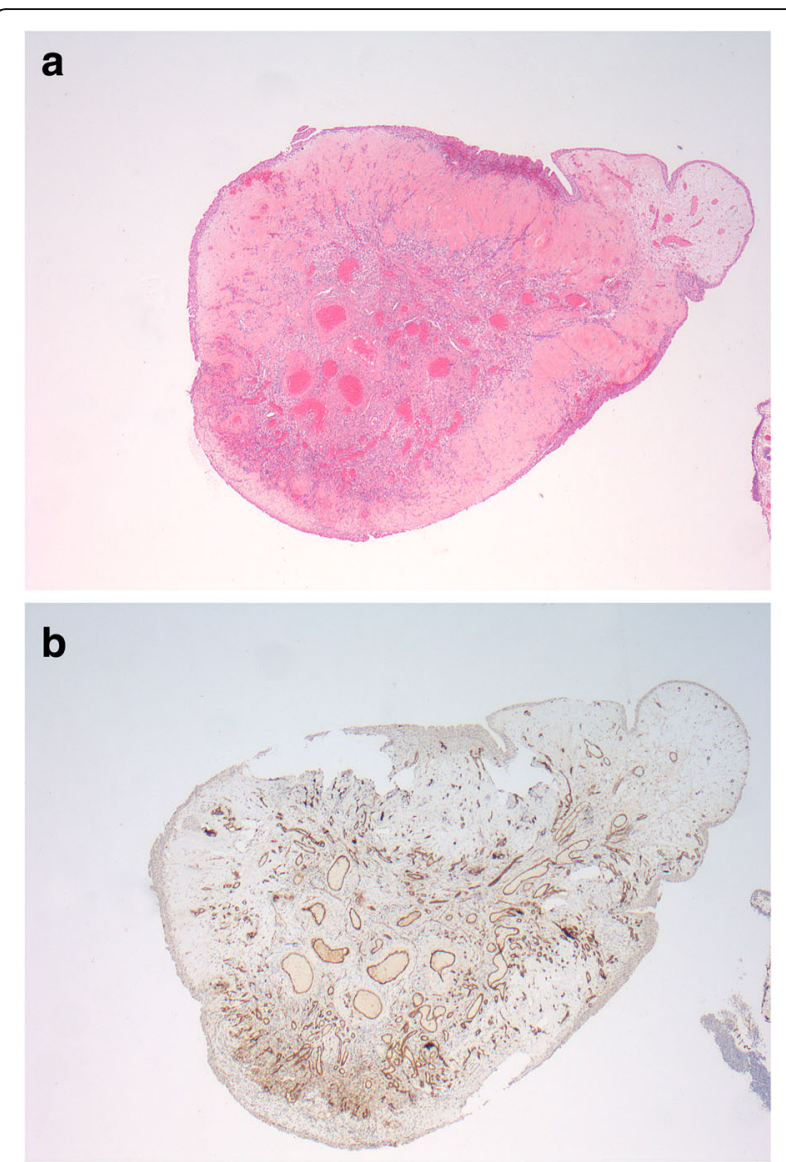

Fig. 2 a, b Hematoxyline-eosine staining and CD31 of the ureteral lesion matching a arteriovenous malformation

and histology confirmed chronic inflammation without evidence of malignancy. Eventually, right renal artery cannulation showed tortuous vessels around the right ureter consistent with AVM, and selective embolization was carried out [6]. The third case was a 29 year old nonCaucasian woman with intermittent gross haematuria and right lower quadrant pain. Urine cytology revealed no malignant cells. Retrograde pyelography showed a filling defect. Uretroscopy was performed and frozen section biopsy revealed benign urothelial mucosa. The polyp was removed using a Greenwald electrosurgical probe [5]. On histopathological examination cases one and three revealed numerous large and small blood vessels superficially located with irregular and asymmetrical walls, confirming the diagnosis of AVM.

Histological examination of the lesion is warranted because on visual inspection it is difficult to distinguish a benign lesion of the ureter from a papillary urothelial neoplasm. Moreover, pre-operatively it is important to know what kind of lesion will be treated so that the most preferable approach can be used. For AVM, laser excision is the best procedure since it diminishes the risk of 
haemorrhage. Selective embolization is also an option, depending on the location of the AVM lesion. However, excisional biopsy with laser coagulation is indicated when a lesion of unknown origin is treated. In our case (case four), cytology of the urine showed moderate to severe atypia. However, on visual inspection and biopsy a benign lesion was suspected; therefore, in this case laser surgery was the preferred approach.

\section{Conclusion}

Arteriovenous malformations (AVM) of the urinary tract are extremely rare. We presented a fourth case of a arteriovenous malformation of the ureter.

\section{Additional files}

Additional file 1: 'Intro en ureter tumorpeg 2: It is videoclip used for Dutch education where our case is used as illustration for different ureter abnormalities and their treatment. (MPEG $37356 \mathrm{~kb}$ )

Additional file 2: Epigenetic influences: Environmental and Lifestyle Influences on Genomics, Proteomics and Metabolomics. (PNG 90 kb)

\section{Abbreviations}

AVM: Arteriovenous malformation; cw: Continuous Wave; FEP: Fibroepithelial polyp

\section{Acknowledgements}

Not applicable.

\section{Funding}

There are no funding sources for this case report.

\section{Availability of data and materials}

Not applicable.

\section{Authors' contributions}

CtD made substantial contributions to conception and design and acquisition of data, or analysis and interpretation of data; has been involved in drafting the manuscript. AH made substantial contributions to conception and design and acquisition of data, or analysis and interpretation of data; been involved in drafting the manuscript. FtK made substantial contributions to acquisition of data. ML revising it critically for important intellectual content; All authors have given final approval of the version to be published. All authors have participated sufficiently in the work to take public responsibility for appropriate portions of the content; and agreed to be accountable for all aspects of the work in ensuring that questions related to the accuracy or integrity of any part of the work are appropriately investigated and resolved.

\section{Ethics approval and consent to participate}

Not applicable.

\section{Consent for publication}

We received written consent for publication from the patient.

\section{Competing interests}

The authors declare that they have no competing interests.

\section{Publisher's Note}

Springer Nature remains neutral with regard to jurisdictional claims in published maps and institutional affiliations.
Received: 3 January 2017 Accepted: 19 June 2017

Published online: 10 July 2017

\section{References}

1. Tekdogan UY, Canakli F, Aslan Y, Han O, et al. Bilateral ureteral fibroepithelial polyps and review of the literature. Int J Urol. 2005;12:98-100. http:// onlinelibrary.wiley.com/doi/10.1111/j.1442-2042.2004.00974.x/full.

2. Childs MA, Umbreit EC, Krambeck AE, et al. Fibroepithelial polyps of the ureter: a single-institutional experience. J Endourol. 2009;23:1415-9. http:// online.liebertpub.com/doi/abs/10.1089/end.2009.0403.

3. Ludwig DJ, Buddingh KT, Kums JJM, Kropman RF, et al. Treatment and outcome of fibroepithelial ureteral polyps: a systematic literature review. Can Urol Assoc J. 2015;9:E631-7. http://www.ncbi.nlm.nih.gov/pmc/articles/ PMC4581930/

4. Sun $Y, X u C$, Wen $X$, et al. Is endoscopic management suitable for long ureteral fibroepithelial polyps? J Endourol. 2008;22:1459-62. http://online. liebertpub.com.proxy.library.uu.nl/doi/abs/10.1089/end.2008.0060.

5. Sech SM, Saboorian MH, Ashfaq R, et al. Polypoid arteriovenous malformation of the ureter. J Urol. 1997;158:1903-4. http://www.jurology. com/article/S0022-5347(01)64166-1/fulltext.

6. Tang CN, Law IC, lu PP, et al. Arteriovenous malformation of the ureter-a rare cause of haematuria. Br J Urol. 1997:80:500-1.

7. Kaplan SA, Brown W, Bixon R, et al. Arteriovenous malformation of ureter. Urology. 1992:40:450-2.
Submit your next manuscript to BioMed Central and we will help you at every step:

- We accept pre-submission inquiries

- Our selector tool helps you to find the most relevant journal

- We provide round the clock customer support

- Convenient online submission

- Thorough peer review

- Inclusion in PubMed and all major indexing services

- Maximum visibility for your research

Submit your manuscript at www.biomedcentral.com/submit
) Biomed Central 